\title{
Engineering active sites for enhancing synergy in heterogeneous catalytic oxidations
}

\author{
James Paterson, a Matthew Potter, a Enrica Gianottib and Robert Raja ${ }^{a *}$
}

a Department of Chemistry, University of Southampton, Highfield, Southampton SO17 1BJ, UK. Fax: +44-2380-593781; Tel: +44-2380-592144; E-mail: R.Raja@soton.ac.uk

b Department of Chemistry IFM \& NIS-Centre of Excellence, University of Turin, Via P. Giuria 7, 10125, Torino, Italy

† Electronic Supplementary Information (ESI) available: [Experimental details, analytical protocols \& refinement results are provided]. See http://dx.doi.org/10.1039/b000000x/

Please cite this paper as:

Chemical Communications, 2011, 1, pp 138-144

The publisher's version of this paper is available here:

http://dx.doi.org/10.1039/c0cc02341h

Related articles by Dr Robert Raja can be found below:

1. R. M. Leithall, V. N. Shetti, S. Maurelli, M. Chiesa, E. Gianotti, R. Raja, Towards understanding the catalytic synergy in the design of bimetallic molecular sieves for selective aerobic oxidations, J. Am. Chem. Soc., 2013, 135, 2915-2918 (doi:10.1021/ja3119064).

2. M. E. Potter, A.J. Paterson, R. Raja, Transition-metal versus heavy-metal synergy in selective catalytic oxidations, ACS Catalysis, 2012, 2, 2446-2451 (doi:10.1021/cs300404u).

3. S. Maurelli, M. Chiesa, E. Giamello, R. Leithall, R. Raja, A HYSCORE investigation of bimetallic titanium-vanadium microporous catalysts: elucidating the nature of the active sites, Chem. Commun., 2012, 48, 8700-8702 (doi:10.1039/c2cc33997h)..

4. M. Vishnuvarthan, A.J. Paterson, R. Raja, A. Piovano, F. Bonino, E. Gianotti, G. Berlier, Gloria, Spectroscopic investigation into the nature of the active sites for epoxidation reactions using vanadium-based aluminophosphate catalysts. Microporous and Mesoporous Materials, 2011, 138, 167-175 (doi:10.1016/j.micromeso.2010.09.010). 


\section{Engineering active sites for enhancing synergy in heterogeneous catalytic oxidations}

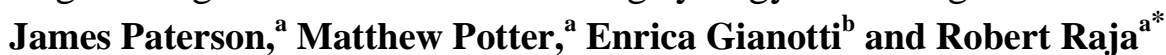

\section{Received (in $X X X, X X X) X$ th $X X X X X X X X X 200 X$, Accepted Xth $X X X X X X X X X 200 X$ \\ First published on the web Xth $X X X X X X X X X 200 X$ \\ DOI: $10.1039 / \mathrm{b} 000000 \mathrm{x}$}

The simultaneous isomorphous substitution of $\mathrm{Al}(\mathrm{III})$ and $\mathbf{P}(\mathrm{V})$ ions, in an aluminophosphate framework, with redox active Co(III) and Ti(IV) metal ions, generates highly active single-site heterogeneous catalysts that exhibit considerable synergy, 5 compared to their corresponding monometallic analogues, in the catalytic epoxidation of olefins.

Engineering multifunctional active sites in microporous solids is a relatively new area of research that exploits the fundamental principles of nanoscience by taking cues from biological and 10 chemical systems. ${ }^{1}$ Microporous solids, such as aluminophosphates ${ }^{2}$ (AlPO's), are three-dimensional framework structures that possess a wide-range of interconnecting pores and channels, where single-site catalytic entities (both redox and Brönsted acid sites) can be judiciously designed for effecting a 15 range of selective oxidation and acid-catalysed transformations. ${ }^{3-6}$ In particular, new bifunctional solids can be designed for the "green" catalytic production of Nylon- $6^{3}$ and, more recently, for the environmentally benign synthesis of vitamin $B_{3}$ and other pharmaceutical and agrochemical intermediates. ${ }^{4,5}$

20 In this study, we have specifically focused our attention on designing bimetallic multifunctional active sites, by isomorphously replacing a few atom percent of the framework ${ }^{7}$ $\mathrm{Al}(\mathrm{III})$ and $\mathrm{P}(\mathrm{V})$ cations with tetrahedrally-coordinated $\mathrm{Co}(\mathrm{III})$ and Ti(IV) ions respectively (Fig. 1). The rationale behind our 25 design strategy was that, the simultaneous incorporation of a tetrahedral Ti(IV) centre, along with a tetrahedral redox site $\{\mathrm{Co}(\mathrm{III})\}$, should facilitate enhancements in the observed synergy in catalytic transformations.

Titanium-based microporous (e.g. titanosilicates such as TS$301)^{8}$ and mesoporous solids (e.g. TiMCM-41) ${ }^{9}$ have proved particularly effective in epoxidation reactions. The high activity and selectivity of these catalysts has been attributed to the local structural environment and coordination geometry of the tetrahedral Ti(IV) centre. Furthermore, the oxophilic nature of 35 the Ti(IV) ion facilitates the coordination of the peroxo species to the metal centre and its concomitant interaction with the olefin via the Eley-Rideal mechanism, ${ }^{10}$ that leads to high catalytic turnovers. Whilst the activities and selectivities of these monometallic catalysts are noteworthy, we believed that, a 40 combination of redox active metal centers that were located within close proximity to a oxophilic species, ${ }^{11}$ such as Ti(IV), should facilitate synergistic interactions, both from a structural and catalytic perspective.

45

\footnotetext{
${ }^{a}$ Department of Chemistry, University of Southampton, Highfield, Southampton SO17 1BJ, UK. Fax: +44-2380-593781; Tel: +44-2380592144; E-mail: R.Raja@soton.ac.uk

${ }^{b}$ Department of Chemistry IFM \& NIS-Centre of Excellence, University of Turin, Via P. Giuria 7, 10125, Torino, Italy

$\dagger$ Electronic Supplementary Information (ESI) available: [Experimental details, analytical protocols \& refinement results are provided]. See http://dx.doi.org/10.1039/b000000x/
}

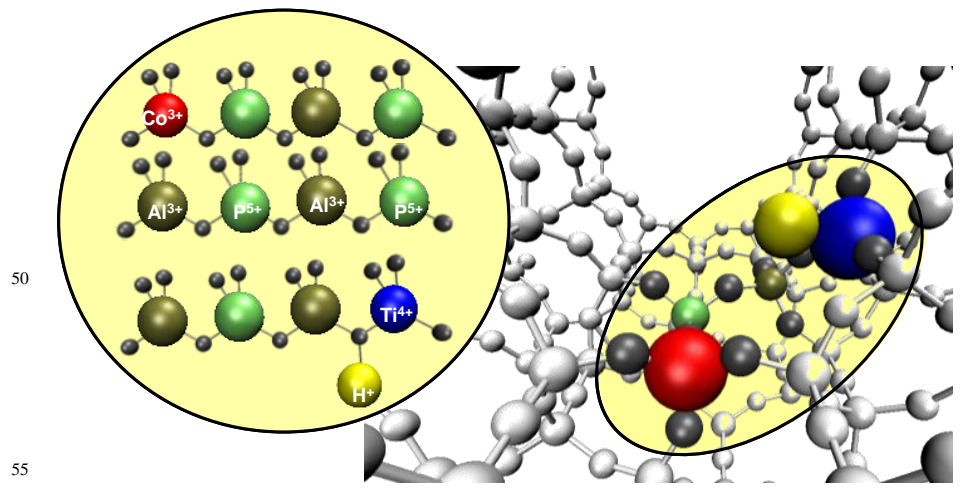

Fig. 1 Graphical representation of an AlPO-framework; where some of the $\mathrm{Al}(\mathrm{III})$ and $\mathrm{P}(\mathrm{V})$ sites have been isomorphously substituted with $\mathrm{Co}(\mathrm{III})$ and $\mathrm{Ti}(\mathrm{IV})$ ions respectively.

${ }_{60}$ The synthetic procedure that we have evolved for synthesising the $\mathrm{Co}^{\mathrm{III}} \mathrm{Ti}^{\mathrm{IV}}$ AlPO-5 catalyst used the following gel composition: $\quad 0.96 \mathrm{Al}: 1.5 \mathrm{P}: 0.03 \mathrm{Co}: 0.03 \mathrm{Ti}: 0.8 \mathrm{SDA}: 50 \mathrm{H}_{2} \mathrm{O}$. This was synthesised by adding $0.0522 \mathrm{~mol}$ of $\mathrm{Al}(\mathrm{OH})_{3}$ to $0.0980 \mathrm{~mol}$ of $\mathrm{H}_{3} \mathrm{PO}_{4}$. The metal precursors ${ }_{65}\left(\mathrm{Co}\left(\mathrm{C}_{2} \mathrm{H}_{3} \mathrm{OO}\right)_{2} \cdot 4 \mathrm{H}_{2} \mathrm{O}\right.$ and $\left.\mathrm{Ti}\left(\mathrm{OC}_{3} \mathrm{H}_{7}\right)_{4}\right)$ were simultaneously added to the above mixture and $\mathrm{N}, \mathrm{N}$ dicyclohexylmethylamine was used as a structure-directing agent (SDA). The final gel was heated at $180^{\circ} \mathrm{C}$ for $2 \mathrm{~h}$ in a teflon-lined autoclave, followed by calcination at $550^{\circ} \mathrm{C}$ in air 70 for $8 \mathrm{~h}$. More details regarding the synthesis can be found in ESI. Typical XRD patterns for the calcined monometallic (CoAlPO-5 and TiAlPO-5) and its corresponding bimetallic analogue (CoTiAlPO-5) are shown in Fig. 2.

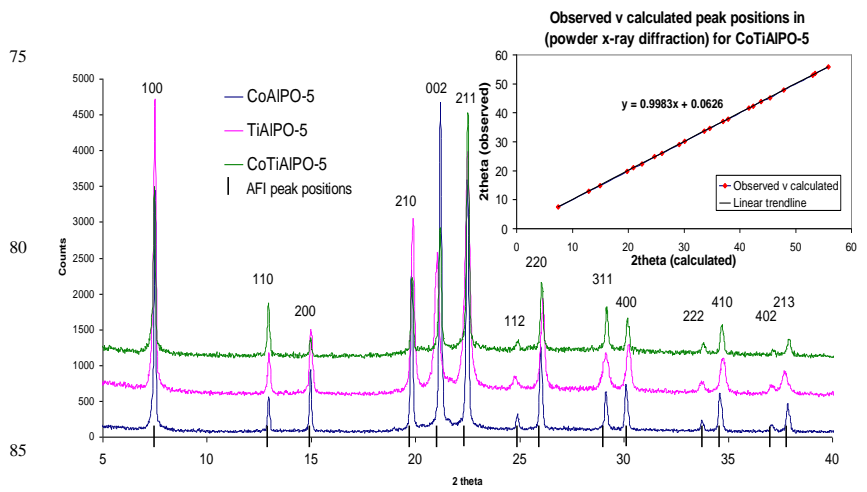

Fig. 2 Powder x-ray diffraction pattern for $\mathrm{Co}{ }^{\mathrm{III}} \mathrm{AlPO}-5, \mathrm{Ti}^{\mathrm{iV}} \mathrm{AlPO}-5$ and $\mathrm{Co}^{\mathrm{III}} \mathrm{Ti}^{\mathrm{IV}} \mathrm{AlPO}-5$. See ESI (and inset) for refinement results.

The indexed pattern for the latter is in good agreement with that 90 reported in the literature for the corresponding monometallic analogues; displaying a high degree of crystallinity with no phase impurities $^{12}$ (see inset and ESI for refinement results). Inductively coupled plasma (ICP) results (Fig. 3A) show a good linear correlation between the individual metal loadings in the ${ }_{95}$ initial gel and in the final calcined catalyst; with more than $90 \%$ 
of the transition metal that was present in the initial gel being incorporated in the (final) calcined AlPO catalyst.

Scanning electron microscopy (SEM, Fig. 3B) also showed a good agreement between the monometallic catalysts and their 5 corresponding bimetallic analogues. In all cases, a spherical morphology was observed and the mean particle sizes that we obtained are in good agreement with previously reported ${ }^{13}$ literature values (10 to $30 \mu \mathrm{m})$. The metal loadings (Table-1) of the monometallic and bimetallic catalysts were ascertained using $10 \mathrm{ICP}$ and AAS (Atomic Absorption Spectroscopy) and BET measurements (see ESI and Table-1) confirmed that all three samples had a comparable surface area, which is in good agreement with the AFI-type materials reported in literature. ${ }^{13}$

\begin{tabular}{lcl}
\hline Catalyst & $\begin{array}{l}\text { Moles of metal/100 } \\
\text { of catalyst (ICP) }\end{array}$ & $\begin{array}{l}\text { Surface Area (BET) } \\
\mathrm{m}^{2} \mathrm{~g}^{-1}\end{array}$ \\
\hline $\mathrm{Co}^{\mathrm{III}} \mathrm{AlPO}-5$ & $3.19 \times 10^{-2}$ & 243 \\
$\mathrm{Ti}^{\mathrm{IV}} \mathrm{AlPO}-5$ & $4.72 \times 10^{-2}$ & 294 \\
$\mathrm{Co}^{\mathrm{III}} \mathrm{Ti}^{\mathrm{IV}} \mathrm{AlPO}-5$ & $4.98 \times 10^{-2}$ & 277 \\
\hline
\end{tabular}

15 Table 1: Metal content and surface area measurements for the monometallic and bimetallic catalysts (see ESI for experimental details).

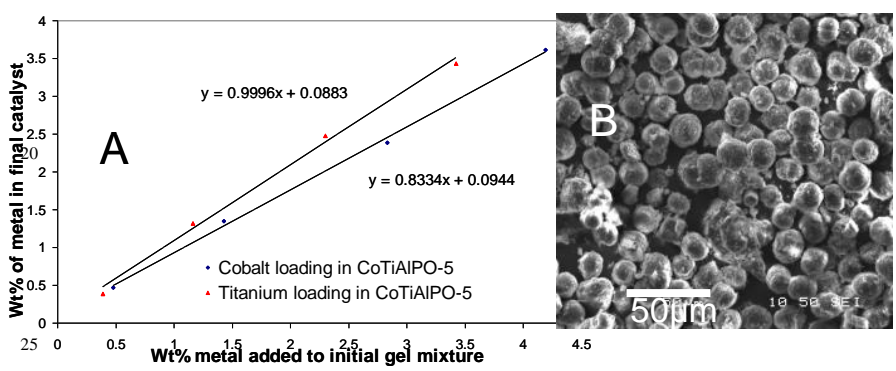

Fig. 3 ICP results for metal loading correlations in the synthesis gel and final catalyst (A) and SEM image of the calcined $\mathrm{Co}^{\mathrm{III}} \mathrm{Ti}^{\mathrm{IV}} \mathrm{AlPO}-5$ (B).

Diffuse reflectance (DR) UV-Vis (Fig. 4) measurements further 30 substantiate the redox capabilities of the cobalt ions in the AlPO5 architecture and provide further evidence for the presence of a greater fraction of tetrahedral Ti(IV) species in the $\mathrm{Co}{ }^{\mathrm{III}} \mathrm{Ti}^{\mathrm{IV}}$ AlPO-5 catalyst (compared to $\mathrm{Ti}^{\mathrm{IV}}$ AlPO-5). The DR UVVis spectrum of calcined CoTiAlPO-5 (Fig.4A, curve a) shows 35 two strong absorptions in the $250-500 \mathrm{~nm}$ range due to LMCT transitions between the oxygen ligands and the tetrahedral $\mathrm{Co}^{\text {III }}$ sites. In the Vis region, the triplet bands that we observe at 530, 592 and $659 \mathrm{~nm}$ can be assigned to the d-d transitions of $\mathrm{Co}^{\mathrm{II}}$ ions in Td coordination. ${ }^{14}$ The presence of this triplet after calcination, 40 suggests that not all of the $\mathrm{Co}^{\mathrm{II}}$ ions can be oxidized to the $\mathrm{Co}^{\text {III }}$ state, which is consistent with our earlier observations. ${ }^{15} \mathrm{We}$ also observe a slight enhancement in the intensity of the triplet band after the reduction treatment (Fig. 4A, curve b). In order to simultaneously detect the cobalt and titanium sites in the ${ }_{45}$ CoTiAlPO-5 sample, it was necessary to completely reduce the catalyst, due to the overlap of the intense UV bands of $\mathrm{Co}^{\mathrm{III}}$ with those of $\mathrm{Ti}(\mathrm{IV})$. Upon reduction in $\mathrm{H}_{2}$ at $400^{\circ} \mathrm{C}$ (Fig. $4 \mathrm{~A}$, curve b), these strong absorptions associated with $\mathrm{Co}^{\mathrm{III}}$ ions completely disappear, and a distinct band at $230 \mathrm{~nm}$ becomes apparent. This 50 latter band can be assigned to isolated tetrahedral Ti(IV) LMCT transitions. ${ }^{16}$ It is also noteworthy that this absorption is shifted to a higher wavelength and becomes significantly broader in the monometallic $\mathrm{Ti}^{\mathrm{iV}}$ AlPO-5 catalyst (Fig. 4B, curve b), when compared with the bimetallic $\mathrm{Co}^{\mathrm{III}} \mathrm{Ti}^{\mathrm{IV}} \mathrm{AlPO}-5$ (Fig. 4B, curve a)
55 analogue, thereby substantiating the presence of octahedral $\mathrm{Ti}(\mathrm{IV})$ sites as oligomeric species or $\mathrm{TiO}_{2}$-like clusters in the monometallic $\mathrm{Ti}^{\mathrm{IV}}$ AlPO-5. ${ }^{17}$ These more coordinated $\mathrm{Ti}(\mathrm{IV})$ species are present in the bimetallic $\mathrm{Co}^{\mathrm{III}} \mathrm{Ti}^{\mathrm{IV}} \mathrm{AlPO}-5$ (shoulder of the UV band extending up to $350 \mathrm{~nm}$ ). However, the absorption 60 band is much sharper when compared with the monometallic $\mathrm{Ti}^{\mathrm{IV}} \mathrm{AlPO}-5$, suggesting the presence of a higher fraction of tetrahedral $\mathrm{Ti}(\mathrm{IV})$ sites, in the bimetallic $\mathrm{Co}^{\mathrm{III}} \mathrm{Ti}^{\mathrm{IV}} \mathrm{AlPO}-5$ catalyst, when compared with that of its monometallic analogue $\left(\mathrm{Ti}^{\mathrm{IV}} \mathrm{AlPO}-5\right)$. For the sake of comparison the DR UV-Vis ${ }_{65}$ spectrum of $\mathrm{Ti}^{\mathrm{IV}} \mathrm{MCM}-41$ (Fig. 4B, curve c) where, the presence of tetrahedral Ti(IV) species can be unambiguously established by deliberately grafting ${ }^{18} \mathrm{Ti}(\mathrm{IV})$ active centres to the inner walls of the mesoporous silica, is also shown.
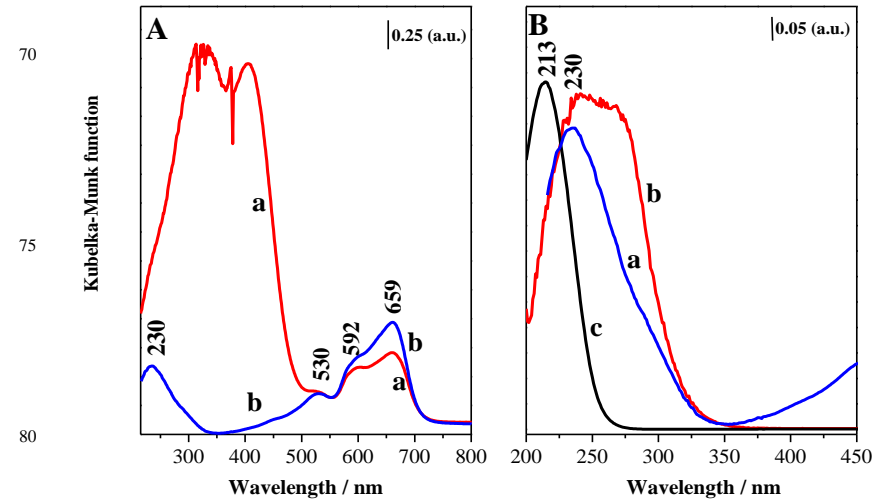

Fig. 4A DR UV-Vis spectra of the oxidized (a) and reduced (b) CoTiAlPO-5 catalyst. Fig. 4B Comparative DR UV-Vis spectra for CoTiAlPO-5 (a), TiAlPO-5 (b) and TiMCM-41 (c). All the spectra are 85 recorded in vacuo at $298 \mathrm{~K}$ after the thermal treatments.

We have recently demonstrated that acetylperoxyborate $(\mathrm{APB})^{19}$ can be used as a solid source of active oxygen when coupled with single-site monometallic aluminophosphate catalysts. The presence of redox $\left(\mathrm{Co}^{\mathrm{III}}\right.$ and $\left.\mathrm{Fe}^{\mathrm{III}}\right)$ sites facilitates 90 the in-situ formation and generation of active oxygen species, which have proved highly effective in the oxidation of hydrocarbons and in the production of fine-chemicals. ${ }^{4,5,20}$ Whilst the selectivities of these catalysed transformations has been high, the overall activities with the monometallic AlPO 95 catalysts, has been, at best modest. ${ }^{20}$ With our bimetallic multifunctional analogues, that have been reported in this study for the first time, we hoped to achieve a synergistic enhancement in the overall catalytic potential, whilst at the same time, maintaining the high selectivities that have been previously 100 associated with APB.

Further to the discovery of the Shell catalyst ${ }^{21}\left(\mathrm{Ti}^{\mathrm{IV}}-\mathrm{SiO}_{2}\right)$ for catalytic epoxidations, there have been numerous efforts devoted to the design of various Ti(IV)-framework-substituted molecular sieves for the epoxidation of olefins. In particular, the emergence 105 of TS-1 was considered a major industrial break-through for selective oxidations with $\mathrm{H}_{2} \mathrm{O}_{2}{ }^{8,22}$ and the use of $\mathrm{Ti}^{\mathrm{IV}} \mathrm{MCM}-41$ with alkyl hydroperoxides for catalytic epoxidations has been highlighted in many reports. ${ }^{9,18}$ Hence, for the purpose of comparison, we have used these two catalysts to benchmark the 110 performance of our monometallic $\left(\mathrm{Co}^{\mathrm{III}}\right.$ and $\left.\mathrm{Ti}^{\mathrm{IV}}\right)$ AlPO-catalysts. Furthermore, using the above approach, we could rationally demonstrate the influence of the synergy and the efficacy of our bimetallic catalyst $\left(\mathrm{Co}^{\mathrm{III}} \mathrm{Ti}^{\mathrm{IV}} \mathrm{AlPO}-5\right)$, when the two active sites were simultaneously substituted into the framework. 


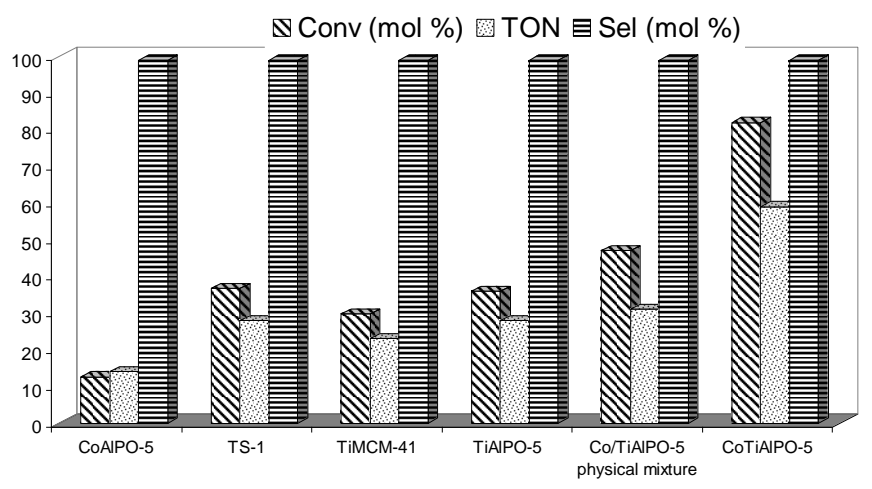

Fig. 5 Synergistic effect of the bimetallic $\mathrm{Co}^{\mathrm{III}} \mathrm{Ti}^{\mathrm{IV}} \mathrm{AlPO}-5$ catalyst in the epoxidation of olefins with APB (see ESI for reaction conditions).

15 The catalytic epoxidation of cyclohexene, using APB as the oxidant, for the monometallic $\mathrm{Co}^{\mathrm{III}} \mathrm{AlPO}-5$ and $\mathrm{Ti}^{\mathrm{IV}} \mathrm{AlPO}-5$ along with that of TS-1 and $\mathrm{Ti}^{\mathrm{IV}} \mathrm{MCM}-41$ is summarised in Fig. 5. Whilst the redox sites in the monometallic Co ${ }^{\text {III }} \mathrm{AlPO}-5$ are considerably inferior (12\% conversion) for the epoxidation 20 reaction, the Ti(IV) sites in TS-1, TiMCM-41 and TiAlPO-5 afford a modest level (30-35\%) of conversion for the same reaction. The bimetallic catalyst $\left(\mathrm{Co}^{\mathrm{III}} \mathrm{Ti}^{\mathrm{IV}} \mathrm{AlPO}-5\right)$, on the other hand, displays a significantly higher level (82\%) of activity when compared with its monometallic analogues or the conventionally 25 used TS-1 where the reaction could occur on the outer surface due to the smaller diameter of the channels $(5.1 \times 5.5 \AA)\}$ and Ti(IV)MCM-41 (30 Å mean pore-diameter), at comparable levels of metal loading (see turnover numbers (TON) in Fig. 5). In order to ascertain whether the higher activities observed with the ${ }_{30} \mathrm{Co}^{\mathrm{III}} \mathrm{Ti}^{\mathrm{IV}} \mathrm{AlPO}-5$ were not just due to the presence of the two metals $\left(\mathrm{Co}^{\mathrm{III}}\right.$ and $\left.\mathrm{Ti}^{\mathrm{IV}}\right)$, we prepared a physical mixture of the two individual catalysts (at similar levels of loading) and the activities observed with the physical mixture were only slightly higher (44\%) than that of their corresponding monometallic analogues. 35 The catalytic trend observed in Fig. 5 clearly demonstrates that the higher activities obtained with the $\mathrm{Co}^{\mathrm{III}} \mathrm{Ti}^{\mathrm{IV}} \mathrm{AlPO}-5$ catalyst arise due to the simultaneous isomorphous incorporation of $\mathrm{Co}(\mathrm{III})$ and $\mathrm{Ti}(\mathrm{IV})$ ions within the AlPO-5 framework.

Extensive catalyst-recycle studies and stringent tests (including 40 hot-filtration experiments), aimed at analyzing the extent of leaching of the metal ions, have been carried out along the lines reported earlier. ${ }^{4,20}$ We did not observe any appreciable decrease in the catalysts' activity or selectivity even after four recycles and analysis of the reactions mixtures by ICP and atomic absorption 45 spectroscopy $(\mathrm{AAS})^{20}$ revealed only trace quantities $(<3 \mathrm{ppb})$ of dissolved metal ions. Furthermore, preliminary computer modeling studies indicate that these two $\left(\mathrm{Co}^{\mathrm{III}}\right.$ and $\left.\mathrm{Ti}^{\mathrm{IV}}\right)$ metal ions in the $\mathrm{Co}^{\mathrm{III}} \mathrm{Ti}^{\mathrm{IV}}$ AlPO-5 catalyst are present within close proximity to each other within the framework structure and, we 50 believe, that it is this close proximity that leads to the enhanced synergy we observe in the catalytic epoxidation. Further x-ray absorption studies (EXAFS and XANES) are currently in progress to establish the exact location of the two metal ions; but the origin and establishment of the synergy is already evident in 55 recently filed patent applications for other industrially significant catalytic oxidations. ${ }^{23}$ We believe, from the preliminary structural analysis, that the simultaneous isomorphous substitution of the $\mathrm{Al}(\mathrm{III})$ and $\mathrm{P}(\mathrm{V})$ sites in the AlPO-5 framework with $\mathrm{Co}(\mathrm{II})$ and Ti(IV) metal ions results in a higher fraction of Co(III) sites in 60 our bimetallic catalysts when compared with their corresponding monometallic (Co ${ }^{\text {III AlPO-5) analogues. }}{ }^{24}$ These (redox) cobalt centres provide the loci for the initiation and generation of freeradical intermediates ${ }^{15,25}$ that are involved in the catalytic epoxidation. Our continued spectroscopic investigations indicate, 65 that it is highly likely, the peroxo species associated with the oxidant preferentially coordinate to the oxophilic Ti(IV) centre in the $\mathrm{Co}^{\mathrm{III}} \mathrm{Ti}^{\mathrm{IV}} \mathrm{AlPO}-5$ catalyst and one can envisage its concomitant interaction with an olefin during catalysis. The benefits of the design strategy in stabilizing the porous

70 framework architecture, thereby facilitating alternate mechanistic pathways for enhancing catalytic reactions, will have huge implications for both fundamental and applied research in this area.

\section{Notes and references}

751 J.K. Nørskov, T. Bligaard, B. Hvolbaek, F. Abild-Pedersen, I. Chorkendorff and C.H. Christensen, Chem. Soc. Rev., 2008, 37, 2163-2171.

2 S.T. Wilson, B.M. Lok, C.A. Messina, T.R. Cannan and E.M. Flanigen, J. Am. Chem. Soc., 1982, 104, 1146-1147.

803 J.M. Thomas and R. Raja, PNAS., 2005, 102, 13732-13736.

4 R. Raja, J.M. Thomas, M. Greenhill-Hooper, S.V. Ley and F.A.A. Paz, Chem. Eur. J., 2008, 14, 2340-2348.

5 R. Raja, Topics in Catal., 2009, 52, 322-332.

6 M. Hartmann and L. Kevan, Chem. Rev., 1999, 99, 635-663.

${ }_{85} 7$ D. Arieli, D.E.W. Vaughan, K.G. Strohmaier and D. Goldfarb, J. Am. Chem. Soc., 1999, 121, 6028-6032.

8 B. Notari, Adv. Catal., 1996, 41, 253-334.

9 P.T. Tanev, M. Chibwe and T.J. Pinnavaia, Nature, 1994, 368, 321323.

9010 D.A. Ruddy and T.D. Tilley, J. Am. Chem. Soc., 2008, 130, 1108811096.

11 J.C. van der Waal, P. Lin, M.S. Rigutto, H. van Bekkum, Stud. Surf. Sci. Catal., 1997, 105, 1093-1100.

12 "Collection of simulated XRD powder patterns for Zeolites" by 95 M.M.J. Treacy and J.B. Higgins, Elsevier Science and Technology, $5^{\text {th }}$ Edition.

13 J.Y. Wang, J.W. Song, C.Y. Yin, Y.Y.Ji, Y.C. Zou and F.S. Xiao, Micro. and. Meso. Mater., 2009, 117, 561-569.

14 R.A. Schoonheydt, R. de Vos, J. Pelgrims and H. Loeman Stud. Surf. Sci. Catal., 1989, 49A, 559-568.

15 J.M. Thomas and R. Raja, Chem. Commun, 2001, 675-687.

16 L. Lenoc, D.T. On, S. Solomykina,B. Echchaed, F. Beland, C.C.D. Moulin and L. Bonneviot, Stud. Surf. Sci. Catal., 1996, 101, 611-620.

17 E. Gianotti, V. Dellarocca, L. Marchese, G. Martra, S. Coluccia and 105 T. Maschmeyer, Phys. Chem.Chem. Phys ., 2002, 4, 6109-6115.

18 T. Maschmeyer, F. Rey, G. Sankar and J.M. Thomas, Nature, 1995, 378, 159-162.

19 Peroxid. Chemie GMBH, US 5462692, 1995.

20 R. Raja, J.M. Thomas, M. Xu, K.D.M. Harris, M. Greenhill-Hooper 110 and K. Quill, Chem. Commun., 2006, 448.

21 Shell Oil, GP 1249079, 1971.

22 G. Bellussi and M.S. Rigutto, Stud. Surf. Sci. Catal., 1994, 85, 177213.

23 University of Southampton, WO2009004342 (2009); EP2170812 115 (2009); GB2450711 (2007).

24 P.A. Barrett, G. Sankar, C.R.A. Catlow and J.M. Thomas, J. Phys. Chem., 1996, 100, 8977-8985.

25 J.M. Thomas, R. Raja, G. Sankar and R.G. Bell, Nature, 1999, 398, 227-230. 